\title{
Very Rare Malposition of a Central Venous Catheter into the Left Internal Mammary Vein in A Patient with Coronary Artery Disease
}

Çıkar Çatışması: Bu makalenin yazarı ve/veya yayınlanması ile ilgili çıkar çatışması yoktur.

Hasta Onamı: Hastadan bilgilendirilmiş onam almıştır.
Conflict of Interest: No conflicts of interest with respect to the authorship and/or publication of this article.

Informed Consent: Informed consent was obtained from the participant.

Cite as: Coșkun E, Okyay RD, Altınay L, Tekin A, Tütün U. Koroner arter hastalığı olan hastada sol iç meme veni içine santral venöz kateterin çok ender malpozisyonu. GKDA Derg. 2019;25(2):133-6.

Öz

Santral venöz kateterizasyon, hastanede yatan hastalarda sıkça kullanılan tanı ve tedavide yardımcı, malpozisyon, rüptür gibi komplikasyonlara neden olabilen girişimsel bir tekniktir. Makalemizde, koroner arter baypas greft cerrahisi preoperatif hazırlıkları yapılan hastada, oldukça ender gözlenen sol iç meme venine olan kateter malpozisyonunu değerlendirmeyi amaçladık. Sol iç meme venine olan bu beklenmedik kateterizasyon literatürde bildirilmiş olmasına rağmen, bu olgu, koroner arter hastasında intraoperatif belirlenen malpozisyonunun ilk raporu gibi görünmektedir.

Anahtar kelimeler: santral venöz kateter, kateter malpozisyonu, sol internal mammarian ven

\section{ABSTRACT}

Central venous catheterization, an interventional technique which is commonly used to aid in diagnosis and treatment in hospitalized patients, may also lead to complications such as malposition and rupture. In this article, we wanted to evaluate a very rare catheter malposition to left internal mammarian vein during preoperative preparation of coronary artery bypass graft surgery. Although this unexpected catheterization into the left internal mammary vein has been reported in the literature. This case seems to be the first report of malposition detected intraoperatively in a patient with coronary artery disease.

Keywords: central venous catheterization, catheter malposition, left internal mammarian vein
Alındığı tarih: 15.06 .2018

Kabul tarihi: 12.09.2018

Yayın tarihi: 30.06 .2019

Elif Coşkun

Bülent Ecevit Üniversitesi Tıp Fak. Sağlık Uygulama ve Araştırma Mer.Kozlu PK: 67600

Kalp ve Damar Cerrahisi Anabilim Dalı Zonguldak - Türkiye drelfco@gmail.com ORCiD: 0000-0002-2275-639X

L. Altinay 0000-0003-4689-1032 A. Tekin 0000-0001-7663-1210

U. Tütün 0000-0002-9661-7632 Bülent Ecevit Üniversitesi Tıp Fak. Sağlık Uygulama ve Araştirma Mer. Kalp ve Damar Cerrahisi Anabilim Dalı Zonguldak - Türkiye

R. D. Okyay 0000-0002-0520-7532 Bülent Ecevit Üniversitesi Tıp Fak. Sağlık Uygulama ve Araştırma Mer. Anestezi ve Reanimasyon Anabilim Dalı Zonguldak - Türkiye

\section{GiRiş}

Santral ven kateterizasyonu, sıvı ve kan infüzyonunu sağlamak, ilaçları uygulamak ve santral venöz basıncı (Central venous pressure, CVP) izlemek için kullanılan yaygın bir prosedürdür ${ }^{[1]}$. Hastalarda santral ven kateterizasyonu malpozisyonu \%6.7 oranında bildirilmiştir ${ }^{[2]}$. Ultrasonografi rehberliği gibi çeşitli yardımcılar kateterlerin başarılı yerleştirilmesini arttırsa da kateter malpozisyonu hâlâ oluşabilmektedir ${ }^{[3]}$.

Yazımızda, açık kalp ameliyatı planlanan hastada, 


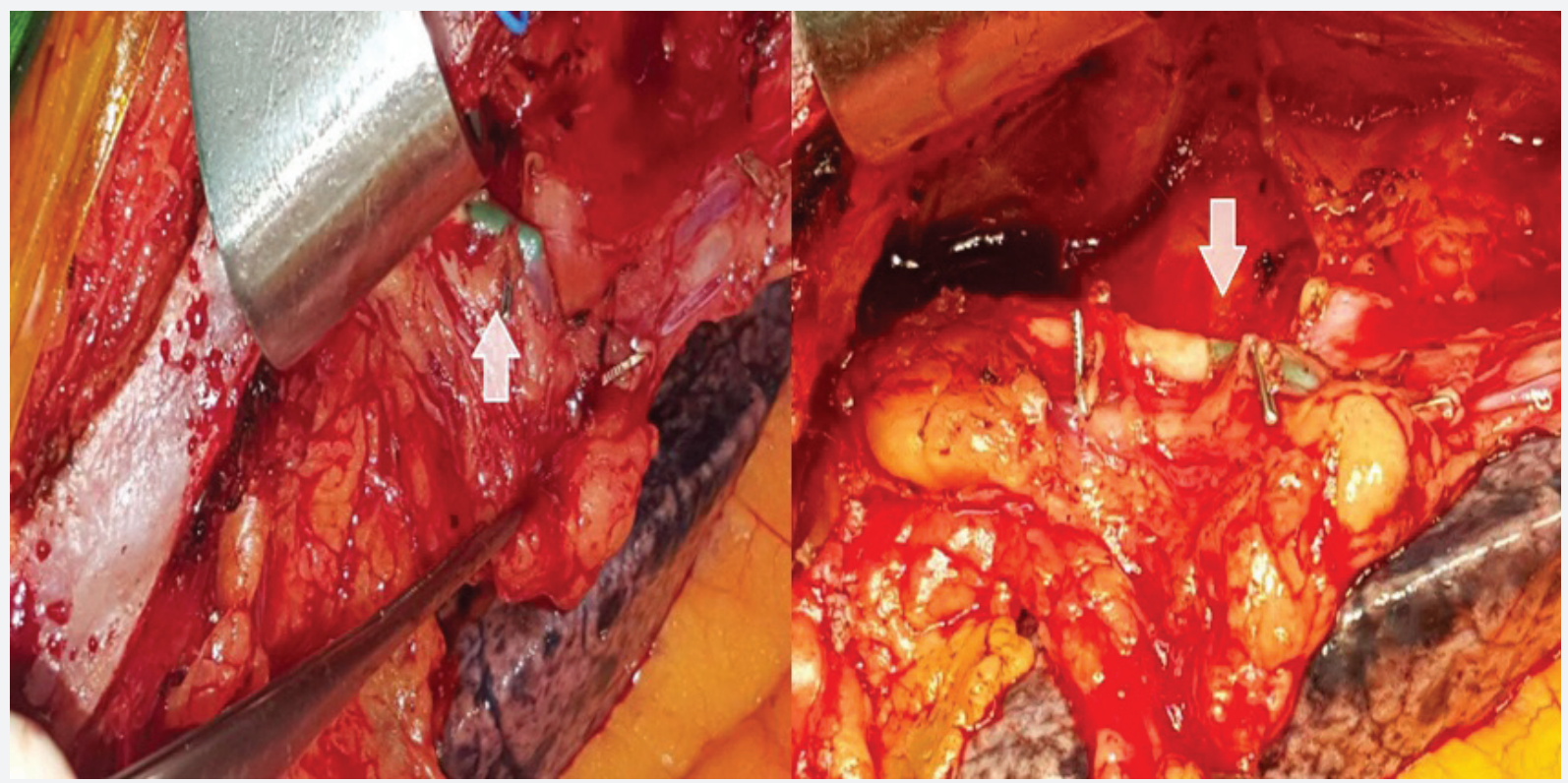

Resim 1. İntraoperatif LIMV'de tespit edilen kateter.

ultrasonografi eşliğinde santral venöz kateter yerleştirildikten sonra intraoperatif fark edilen kateter malpozisyonu olgusunu sunduk. Sol internal mammarian vene (Left Internal Mammarian Vein-LIMV) olan bu beklenmedik malpozisyon literatürde bildirilmiş olmasına rağmen, koroner arter hastasında intraoperatif belirlenen ilk rapor gibi görünmektedir.

\section{OLGU}

Yetmiş üç yaşında maden işçisi erkek hastada, nonspesifik göğüs ağrısı nedeniyle yapılan diagnostik koroner anjiyografi neticesinde, koroner arter hastalığı saptanarak aorta koroner baypas (Coronary Artery Bypass Grafting, CABG) planlandı. Öyküsünde 10 yıldır kronik obstrüktif akciğer hastalığı ve 35 yıldır Tip 2 diabetes mellitus olduğu öğrenildi. Fizik muayenesinde herhangi bir patoloji saptanmadı. Hastanın sessiz tiroid ve ötiroid hasta sendromu ön tanıları ile takip ve tedavisi devam ederken akut koroner sendrom gelişmesi üzerine acil olarak 4 damar koroner arter baypas greft ameliyatına alındı.

Hastanın preoperatif (pre-op) bilateral karotis arter renkli doppler ultrasonografisinde; sağ internal karo- tis arter lümeninde $\% 50$ darlığa neden olan mikst tipte plak belirlendiği için anestezi uzmanı tarafından santral kateter girişiminin sol taraftan yapılmasına karar verildi.

Anestezi uzmanı tarafından, MyLab 30 Gold Cardiovascular US System (Esaote Biomedica, Genova, İtalya) ile ultrasonografi eşliğinde, santral venöz kateter Certofix Duo V 7207 FrX8" $(20 \mathrm{~cm})$ (Braun, Hessen, Almanya) sol karotis ön üçgen (Carotid Anterior Triangle, CAT) bölgesinden girişim yapılarak sorunsuz olarak yerleştirildi. İşlem sırasında herhangi bir zorluk yaşanmadı.

CABG için median sternotomiyi takiben sol ön iç meme arteri (Left Anterior Descending Artery, LAD) anastomozunda kullanılmak üzere, sol internal mammarian arter (Left Internal Mammarian Artery, LIMA) diseksiyonu yapıldığı sırada santral venöz kateterin sol iç meme veninde (Left Internal Mammarian VeinLIMV) olduğu görüldü (Resim 1). Bunun üzerine malpoze santral venöz kateter çıkarıldı. Femoral bölgeden santral damar yolu açılarak ameliyata devam edildi. Bu komplikasyondan dolayı sorun yaşamayan 4 damar koroner arter baypas greft cerrahisi uygulanan hasta post-op 6 . gününde sorunsuz taburcu edildi. 


\section{TARTIŞMA}

Kateter komplikasyonlarını mekanik komplikasyonlar (arteryel delinme, pnömotorax, hematom), infeksiyöz komplikasyonlar ve trombotik komplikasyonlar olarak gruplandırabiliriz ${ }^{[4]}$.

Santral damar yolu için öncelikli olarak sağ internal juguler ven, sonrasında sırası ile sol internal juguler ven, subclavian venler veya femoral venler önerilmektedir ${ }^{[5]}$. Olgumuzda sağ internal karotis arterde darlık oluşturan plak olması nedeniyle doğabilecek girişimsel komplikasyonlardan sakınmak için ilk olarak sol internal juguler ven girişimi denenmiştir. Sol internal juguler ven yaklaşımında, sol innominat ven sağ innominat venden anatomik olarak farklı olduğu için kateterin doğru yere yönlendirilmesini güçleştirdiğini düşünmekteyiz.

Kateter yerleştirilirken kılavuz telin ilerletilmesi sırasında dirençle karşılaşılması malpozisyon açısından bizi uyarmalı ve kateterin çalışmaması, yeteri kadar hızlı kan alınıp verilememesi kateter malpozisyonunu akla getirmelidir. Ne yazık ki kateterin yerleştirilmesiyle oluşabilecek subjektif yakınmalar hasta entübe edildikten sonra kateter yerleştirildiği için bilinemedi. Hastamızda herhangi bir dirençle karşılaşılmadı ve tüm lümenlerden kan aspirasyonu başarıyla yapılabildi, oysaki kateter olması gereken lokalizasyonda değildi. Nitekim Holhlrieder ve ark. ${ }^{[6]}$ santral kateter lümenlerinden kanın aspire edilebilmesinin kateter malpozisyonunu ekarte ettirmeyeceğini belirtmekte-

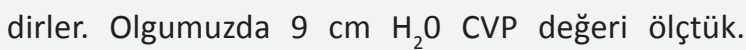
Hikayesinde maden işçiliği ve KOAH olduğu için hafif yüksek olmasından şüphelenmedik.

USG'nin kanülasyona kılavuzluk etmesi günümüzde en iyi uygulama olarak kabul edilmekte ve geleneksel "kör" yöntem ile karşılaştırıldığında, başarısız kateterizasyonları ve komplikasyonları azaltmaktadır [7]. Kateter yerini doğrulamak için göğüs röntgeni yanında, transtorasik ekokardiyografi (TTE) ile kombine vasküler USG önerilmektedir ${ }^{[2]}$. TTE tarafından sağ atrium ve ventrikül kolayca gözlenebilmektedir
[8]. Ancak ekstra atriyal malpozisyonda, olası tüm konumlar tespit edilemeyebilir. Bu durumlarda ise posterior-anterior akciğer grafisi yeterli yanında lateral akciğer grafisi ve hatta bilgisayarlı tomografi ile ayırıcı tanı yapılması önerilmektedir ${ }^{[9]}$. Kalp kapağı cerrahisi operasyonlarında standart uyguladığımız transözefagial ekokardiyografi (TEE), koroner baypas operasyonlarında rutin uygulanmadığından kateterin yerinde olmadığı LIMV görülene kadar farkedilemedi. Ayrıca, olgumuzda ultrasonografi kullanılması malpozisyonu önleyememiştir. Mediasten açıldığı ve innominate ven ile sağ atrium yapıları gözle görüldüğü, palpasyon ile kateterin yerinde olup olmadığı kontrol edilebildiği için kateterin malpozisyonu intraoperatif fark edilebildi.

Sonuç olarak, santral venöz kateter uygulaması sırasında herhangi bir görüntüleme ve monitorizasyon yöntemi kullanılmadığında malpozisyonun gözden kaçabileceği unutulmamalıdır. Deneyimli kişilerce ultrasonografi eşliğinde yapılsa bile, işlem sonrasında şüpheci olunması ve doğrulama yapılmasının gerektiğini gördük. Özellikle mediastenin göz önünde olmadığı intraoperatif durumlarda doğrulama için TTE/TEE ile de değerlendirme yapılmasını önermekteyiz. Rutin ve standart uygulama olmasına rağmen, santral venöz kateterizasyonun komplikasyon oluşturma potansiyeli her zaman akılda tutulmalıdır.

\section{KAYNAKLAR}

1. Lim AJ, Jee $\mathrm{CH}$, Kwak $\mathrm{KH}$. The malposition of a central venous catheter through a sheath introducer via the left internal jugular vein. Medicine 2017;96:24. https://doi.org/10.1097/MD.0000000000007187

2. Smit MJ, Raadsen R, Blans JM, Petjak M, Van de Ven PM, Tuinman RP. Bedside ultrasound to detect central venous catheter misplacement and associated iatrogenic complications: a systematic review and metaanalysis. Critical Care 2018;22:65. https://doi.org/10.1186/s13054-018-1989-x

3. Carlos JR, Linda P. Central venous catheter intravascular malpositioning: causes, prevention, diagnosis, and correction. West J Emerg Med 2015;16:658-64. https://doi.org/10.5811/westjem.2015.7.26248

4. McGee DC, Gould MK. Preventing complications of central venous catheterization. N Engl J Med. 
2003;348:1123-33.

https://doi.org/10.1056/NEJMra011883

5. Guth AA. Routine X-rays after insertion of implantable long-term venous catheters: Necessary or not? American Surgery 2001;67:26-9.

6. Hohlrieder M, Schubert HM, Biebl M, Kolbitsch C, Moser PL, Lorenz IH. Successful aspiration of blood does not exclude malposition of a large-bore central venous catheter. Can J Anaesth. 2004;51:89-90. https://doi.org/10.1007/BF03018557

7. Lalu MM, Fayad A, Ahmed O, Bryson GL, Fergusson DA, Barron CC, et al. Ultrasound-guided subclavian vein catheterization: a systematic review and meta-analysis. Crit Care Med. 2015;43(7):1498-507.
https://doi.org/10.1097/CCM.0000000000000973

8. Douglas PS, Garcia MJ, Haines DE, Lai WW, Manning WJ, Patel AR, et al. ACCF/ASE/AHA/ASNC/HFSA/HRS/ SCAI/SCCM/SCCT/SCMR 2011 appropriate use criteria for echocardiography. J Am Coll Cardiol. 2011;57(9): 1126-66. https://doi.org/10.1016/j.jacc.2010.11.002

9. Stone $A P$, Hass MS, Knackstendt SK, Jagannath P. Malposition of a Central Venous Catheter Into the Right Internal Mammary Vein: Review of Complications of Catheter Misplacement. Vascular and Endovascular Surgery. 2012;46(2):187-9.

https://doi.org/10.1177/1538574411433288 